\title{
Development Trend Research of Experimental Psychology
}

\author{
Huajie Sui ${ }^{1}$ \\ School of humanities, Jiangxi University of Traditional \\ Chinese Medicine .Jiangxi Nanchang, 330004, China \\ e-mail: 510563704@qq.com
}

\author{
Boyuan Song ${ }^{2, *}$ \\ School of humanities, Jiangxi University of Traditional \\ Chinese Medicine Jiangxi Nanchang, 330004, China \\ e-mail: 6071620@qq.com
}

\begin{abstract}
Psychological Science has come a long and complicated road. However, from the early days of psychology from the development of psychological science on with the actual needs are closely linked. It pointed out that this is very important. Obviously, the first psychological laboratory is to train and educate children in the targeted establishment of educational institutions, or in a medical institution established. In recent years, with the development of scientific research in psychology deepening, with the rapid development of modern science and technology and social psychology research and development there are some new trends, research methods showed many new features. This focus is reflected in the following aspects: Ecological research ideas; interdisciplinary research methods and cross-cultural characteristics; research means of integration and modernization; a large number of multivariate statistical techniques; and research in all aspects of computerization.
\end{abstract}

Keywords-Philosophy and psychology; development; law; unity; trend

\section{INTRODUCTION}

To learn psychology, you must know the relationship between it and the other disciplines, psychology and philosophy, physiology, social sciences are directly related [1-5]. And close to psychology and philosophy, but not fixed, but with the development of the times constantly evolving [6]. Can be roughly divided into the relationship between psychology and philosophy developed in two phases, the distinction between the two phases was marked by the birth of psychology as an independent scientific fields, the relationship before and after the two different stages, psychology and philosophy occurred major changes $[7,8]$.

The ultimate goal of this paper is to explore the development law of psychology, and this exploratory work is from the perspective of psychology, philosophy, and therefore, it is necessary at the beginning of the article about the knowledge of psychology, philosophy elaborate. In the history of the development of psychology, the relationship between psychology and philosophy, is the most dramatic and the most controversial. Psychology, philosophy of exploration, is crossing or cross-border study psychology and philosophy $[9,10]$.

For the development of psychological study, the researchers not only to explain the study results, but also to make general conclusions based on the results, so the results can be adapted to a more general, more universal situations or people [11]. The general conclusion of the study is based on research results and their interpretation means to make research findings can be applied or extended to other contexts or populations reasonable degree. The accuracy of the general conclusions of the study depends directly on the reasonableness of the interpretation of results [12]. General developmental psychology research findings include two aspects of internal and external research. Study of the Internal generality is a concrete reflection of the internal validity of the study, including three dimensions variables, methods and general and other mental processes studied. Research is the general exterior concrete study of external validity, mainly between the subjects studied several dimensions between general and other situations [13].

From the interpretation of the results of the process to come to a general conclusion, in fact, the results of the study process theoretical analysis. It reveals the theoretical significance of the research is the main problem to be solved by theoretical analysis, theoretical analysis of the adequacy of whether the in-depth, directly determines the value and significance of the study. On the basis of qualitative analysis and quantitative analysis, theoretical analysis of the psychological development of the phenomenon beyond description, by means of theoretical thinking on a series of empirical material thinking process, and finally rose to the theoretical understanding, reveal the nature and laws of psychological development.

\section{CATEGORY PSYCHOLOGY}

Philosophy of understanding about psychology, foreign scholars believe that philosophical problems of psychology is the basic theory of psychology general psychology, history of psychology and other branches of psychology exist, raised to the level of a philosophical theory to carry out scientific analysis and research. Some scholars believe that the task of psychology is the study of philosophy and psychology research psychology philosophical meaning, specifically, is to examine the concept of presets and significance of psychology, and psychology in order to open the way for the further development of philosophy. Clearly, these various viewpoints, although already touched philosophical understanding of psychology, but still can not derive the true philosophy of psychology understanding. Psychology research methods were shown in Fig. 1. 


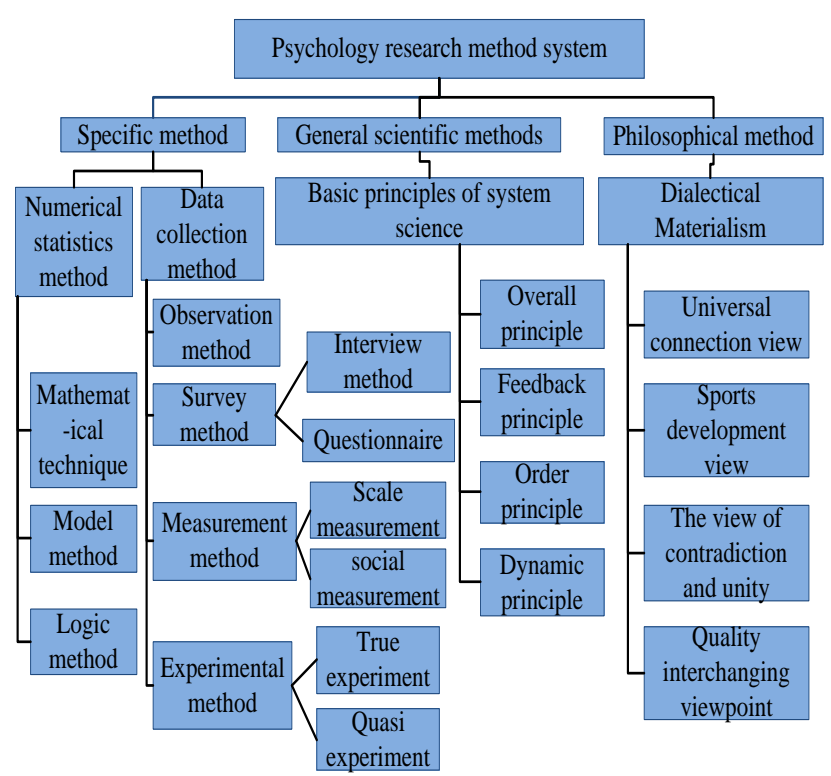

Figure 1. Psychology research methods

Philosophy and psychology is different from the philosophy of psychology, scientific psychology and human psychology, it is not a set of specific, ready-made and tangible psychological knowledge system, to play a knowledge function to resolve the psychological problems, but a theory of wisdom, bear a variety of psychological knowledge and critical reflection functions. The direct object of this reflection and critique is that various premises logic or meta-theory of psychological knowledge systems (including psychological description of the phenomenon, causal explanation, theoretical generalization and psychology concept), and these premises logic or meta-theory to a variety of psychological knowledge system is essential. Through them, a variety of specific forms of psychological knowledge system was able to generate legitimate. Therefore, to explore the philosophy of psychology psychologist First Reflections on psychology research object prior theoretical supposition, the second is a pretheoretical reflection psychologist preset on psychological research methods. Psychology lifelong development stage was shown in Tab. 1.

TABLE I. PSYCHOLOGY LIFELONG DEVELOPMENT STAGE

\begin{tabular}{|l|l|}
\hline Stage & Age bracket \\
\hline Before birth & From conception to birth \\
\hline Infancy & $\begin{array}{l}\text { From term birth to about } 18 \\
\text { months }\end{array}$ \\
\hline Early childhood & From about 18 months to ages 6 \\
\hline Late childhood & From ages 6 to about 13 \\
\hline Puberty & From ages 13 to about 20 \\
\hline Early adulthood. & From ages 20 to about 30 \\
\hline Mid-adulthood & From ages 30 to about 65 \\
\hline early adulthood. & After about 65 years old \\
\hline
\end{tabular}

\section{ANALYSIS AND PRESENTATION OF DEVELOPMENTAL PSYCHOLOGY RESEARCH FINDINGS}

\section{A. Qualitative analysis of the development of research results}

Qualitative analysis is based on the development of the results of the "quality" of the analysis is the application of analysis and synthesis, comparison and classification, inductive and deductive logic analysis and other methods, the Institute is eligible data were thinking process, thus recognizing the essential characteristics of the study reveals its occurrence, development of the law, to build a research and theoretical interpretation of the results provide evidence. Overall, the qualitative analysis of the following characteristics:

(1) Qualitative analysis is based on the description on the basis of logical analysis or inference. For example, in a study of children in the formation of the concept of death, researchers first through interviews, collect a lot of data, then by logical analysis, summarized the three essential characteristics of the concept of death, that is universal, non-functional and irreversible resistance, and thus establish a theoretical framework, the research process and the formation of law concept of death.

(2) Qualitative analysis focuses explore the psychological phenomenon in the development process or behavior, "meaning." For example, studies in a face recognition and emotional causes, researchers use interviewing subjects to a series of questions, we collected a large number of children on what emotional experience, how to describe and explain their own experience and Cause someone else's emotions and other aspects of data through logical analysis, the general rule of emotional development.

(3) Qualitative analysis tend to be summarized and analyzed the results. For example, the researchers deep into the real life in kindergarten or elementary school, it was observed interpersonal behavior of children. Actual observed behavior conflicts (including quarrels and fights) is a widespread phenomenon among children. To this end, they carried out the issue further special insight into the results show that children in the conflict between the conflict provoked some people always higher social status of children. In this regard, they put forward a different interpretation, and be tested in further studies.

(4) The qualitative analysis not only pay attention to the findings of the analysis, more emphasis on process and relationship analysis. For example, aim to study the issue of children in conflict is to reduce, control the behavior of children in conflict, just analyze the situation and provoke the conflict's end is hard to achieve their goals, but also to deal with children in conflict and subsequent interactions, mood and cognitive changes and strategies used were analyzed, in order to better and more efficiently find solutions to problems.

Developmental psychology research qualitative analysis generally involves two steps. First, determine 
qualitative objective analysis. Target of qualitative analysis is to find the relationship between variables (correlation, causation or other relationships). For example, the researchers want to study the characteristics of selfconsciousness of primary school children, designed a series of questions, the use of children's self-evaluation questionnaire test of objectivity. Results analysis can be in two ways: one is the result of the level of children's selfevaluation and its activities (such as grades, test scores, etc.) were compared to investigate the degree of accord between the two, the second is the child's self-evaluation with others of their evaluation (such as teachers, students and parents evaluate) were in line with the degree of comparison study between them. In this case, to determine the extent of compliance with the qualitative comparison between the two is the goal of the analysis. Secondly, the objective qualitative analysis of the study results to collate, analyze and then apply the method to find the relationship between the variables, and to explore its own rules. In this step requires the use of qualitative analysis about logical methods, such as analysis and synthesis, induction and deduction, comparison and classification, abstract and concrete, etc. Psychology study population and sample was shown in Fig. 2.

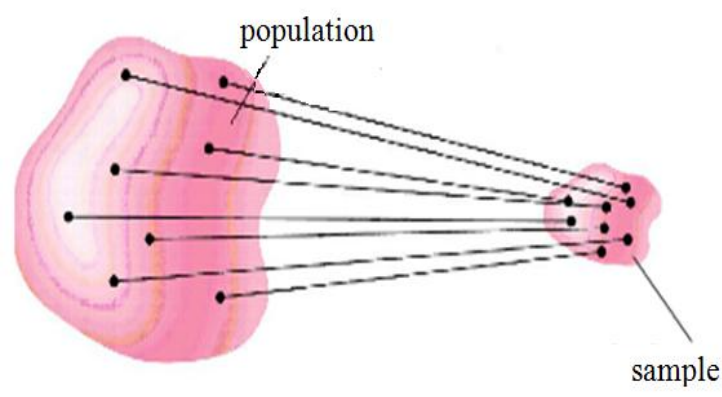

Figure 2. Psychology study population and sample

\section{DEVELOPMENT OF RESEARCH RESULTS}

Since the development of the Institute of Psychology of data obtained has variability and statistical regularity characteristics, therefore, the researchers can not simply put the overall results of the sample analysis as the basis, but should be based on the variability of the data and statistical regularity Opposites, quantitative analysis of the study results. Quantitative analysis of the results can help us to extract data from complex chaos in the regularity of information, thereby enabling the researchers to deeply understand, fully describe accurately extrapolate and predict changes in the study and development, making research who make or test the hypothesis, based on the theory of constructivism. Using proper statistical methods to data collected quantitative analysis can reveal the characteristics and laws of the data, draw scientific conclusions. According to different classification criteria may be quantitative analysis is divided into different categories, of which the most commonly used descriptive statistics, inferential statistics and multivariate statistical analysis.

Descriptive statistics include preliminary collation of data, metrics central tendency and dispersion trends and correlation between metrics and other aspects, which aims to make numerous data show clear and intuitive characteristics of the object, in order to facilitate further analysis. Inferential statistical inference mainly discussed the overall situation through data. Statistical inference population parameter estimation method includes features and hypothesis testing in two parts, which are divided into parametric hypothesis testing hypothesis tests and nonparametric test. Psychology book price trends were shown in Fig. 3.

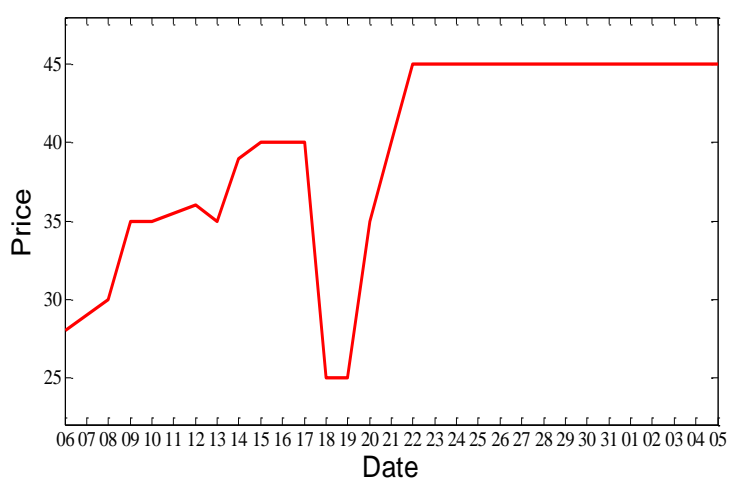

Figure 3. Psychology book price trends

Descriptive statistics and inferential statistical methods are mostly designed for only a single factor in terms of the argument, but the factors that affect mental development is not a single, but diverse, including both genetic factors, physiological maturity factors, nutrition environmental, educational factors, family, school and society, including the development of internal contradictions or psychological power and other subjective factors. One of the factors can be divided into a number of different aspects. Therefore, the experimental design than the single factor experimental design multivariate more in line with the actual situation, efforts should be made to collect data cross multiple variables, in order to reveal the connections between things from the analysis of these data. Commonly used methods of multivariate statistical analysis trend analysis, regression analysis, factor analysis, time series analysis, path analysis, the minimum distance analysis, meta-analysis. In addition, since the amount of computation experimental study multivariate analysis designed generally large, human calculation is difficult to complete, so, multivariate analysis is usually done by a computer.

\section{CONCLUSIONS}

In short, developmental psychology research object has any qualitative and quantitative aspects, these two aspects are closely linked and inseparable. Therefore, the development of psychological research can be carried out both qualitative analysis from a qualitative point of view, and can be quantitatively analyzed in terms of quantity; at the same time, qualitative analysis and quantitative analysis is also inextricably linked, both as foundation, complement each other, can not be one-sided emphasis on the one hand while on the other hand neglected. The 
results explain in many ways, but have a certain logic rules and procedures based on inference, as inference, deduction, induction and causal inference method. When using these methods to objectively explain the findings, not to explain the theory of a result of misinterpretation. In addition, the interpretation of the results, the need to have an overall grasp of all the data, not just selected explanatory variables local data relationships.

\section{REFERENCES}

[1] Koffka K. Principles of Gestalt psychology[M]. Routledge, 2013.

[2] Mowday R T, Porter L W, Steers R M. Employee—organization linkages: The psychology of commitment, absenteeism, and turnover[M]. Academic Press, 2013.

[3] Mertens D M. Research and evaluation in education and psychology: Integrating diversity with quantitative, qualitative, and mixed methods[M]. Sage Publications, 2014.

[4] Gregory R L. Eye and Brain: The Psychology of Seeing: The Psychology of Seeing[M]. Princeton university press, 2015.
[5] Tomasello M. The new psychology of language: Cognitive and functional approaches to language structure[M]. Psychology Press, 2014.

[6] Lindsay P H, Norman D A. Human information processing: An introduction to psychology[M]. Academic Press, 2013.

[7] Keller F S, Schoenfeld W N. Principles of psychology: A systematic text in the science of behavior[M]. BF Skinner Foundation, 2014.

[8] Parker I. Discourse Dynamics (Psychology Revivals): Critical Analysis for Social and Individual Psychology[M]. Routledge, 2014.

[9] Bargh J A. Social psychology and the unconscious: The automaticity of higher mental processes[M]. Psychology Press, 2013.

[10] Adler A. The practice and theory of individual psychology[M]. Routledge, 2013.

[11] Cosmides L, Tooby J. Evolutionary psychology: New perspectives on cognition and motivation[J]. Psychology, 2013, 64.

[12] Eysenck H J, Eysenck S B G. Personality Structure and Measurement (Psychology Revivals) [M]. Routledge, 2013.

[13] Swets J A. Signal detection theory and ROC analysis in psychology and diagnostics: Collected papers[M]. Psychology Press, 